\title{
The first record of a homeotic wing pattern aberration in an Australian butterfly from a specimen of Papilio aegeus ormenus Guérin-Méneville, 1830 (Lepidoptera, Papilionidae)
}

\author{
Graham A. Wood ${ }^{1}$, John E. Nielsen ${ }^{2}$ \\ 1 P.O.Box 622, Herberton, QLD, 4887,Australia; aainsects@aainsects.com.au \\ 2 Unaffiliated, Downer, Australia \\ http://zoobank.org/BA545F48-23AC-4818-9D92-AF327028FDB4
}

Received 15 November 2016; accepted 22 August 2017; published: 6 November 2018

Subject Editor: Jadranka Rota.

\begin{abstract}
A specimen of Papilio aegeus ormenus with a forewing/hindwing pattern homeosis is described from Mer Island, Torres Strait, Queensland, Australia. This represents the first record of a butterfly specimen with wing pattern homeosis from Australia.
\end{abstract}

\section{Introduction}

Homeosis is a developmental aberration where one structure is converted, either completely or partially, into another (Sibatani 1980). In butterfly wing patterns, Sibatani (1980) recognised that homeosis manifested as a replication of wing patterns between the dorsal and ventral surfaces of the same wing, or between corresponding areas of the forewing and hindwing. In the case of forewing-hindwing pattern homeosis, Sibatani (1980) noted that the area of wing membrane affected tended to be bounded anteriorly by veins $\mathrm{M}_{1}-\mathrm{M}_{2}$, which led him to present a hypothesis that homeotic aberrations are due to mutations of the bithorax group of genes. Mutations of these genes were observed by Lewis (1978) to result in structure homeosis between segments in Drosophila melanogaster, with the genes producing the homeotic mutations always observed to occur in an identical sequence along the chromosome to where the mutations manifested along the segmentation of the adult insect. Similarly, Sibatani (1980) inferred that the distribution of homeosis on butterfly wings would always be posterior to veins $\mathrm{M}_{1}-\mathrm{M}_{2}$, reflecting genetic compartmentalisation of the butterfly wing pattern, as the boundary of the genetic compartment lies in the vicinity of these veins.

Based on an extensive survey of museum collections, Sibatani (1980; 1983a; 1983b) recorded a total of 358 specimens with homeotic aberrations from 16 Lepidoptera families. Although the majority of these aberrations occurred in butterflies (Papilionoidea), Sibatani (1983a) concluded that this probably reflected the popularity of 'collectable' species (e.g. fritillaries; Nymphalidae: Heliconiinae: Argynnini) rather than predisposition of any family to producing homeotic aberrations. The surveys also found that the majority of homeotic aberrations were of the forewinghindwing homeosis type (326 specimens), with dorsal-ventral homeosis less frequently represented (32 specimens) (Sibatani 1983a, 1983b). Specimens were also recorded from all continents except Australia (Sibatani 1980, 1983a, 1983b). Here, we describe a forewing-hindwing type wing pattern homeosis from a specimen of Papilio aegeus ormenus collected by Wood from Mer Island, Torres Strait, Queensland, the first report of wing pattern homeosis for any Australian butterfly. 


\section{First report of a homeotic wing pattern aberration from an Australian butterfly}

The homeotic specimen reported here (Figure 1) is a female of Papilio aegeus ormenus that was reared from the progeny of two females collected by Wood on Mer Island in the Torres Strait, Queensland, on 28 March 1984 (in G.A. Wood collection). The females of P. aegeus ormenus are polymorphic (Hancock 1983; Parsons 1999); both the specimen reported here and the females from which the cohort were obtained were of form polydorina, which is inferred to mimic Pachliopta polydoras (Linneaus, 1758), a toxic Troidine Papilionid (Hancock 1983). The cohort of larvae obtained were reared on Mer Island using the foliage of Citrus spp. (Rutaceae) as the hostplant. However, pre-arranged logistic arrangements meant that some of the cohort needed to be moved by light aircraft as they were in the process of pupating. While a number of these pupae showed obvious deformities, presumably due to interference during ecdysis, no external deformities were noted for the pupa of the homeotic specimen.

The female of $P$. aegeus ormenus f. polydorina normally has the forewings dark brown on both surfaces, with the wing membrane distal to the discocellular cell white-grey with veins broadly dark brown. The hindwing has a broad patch of white scaling centrally, with a series of brown-red subterminal lunules and a limited number of diffuse iridescent blue lunules towards the tornus. The underside is identical to the upperside, with the exception of the hindwing which has a well-developed series of iridescent blue lunules medial to the brown-red lunules (Parsons 1999). In the homeotic specimen (Fig. 1), the upperside is normal, while the underside shows a forewing-hindwing type homeotic aberration on the right pair of wings when viewed ventrally. The homeotic pattern occurs on the forewing and is restricted to the wing membrane bordered by the discocellular cell and veins $\mathrm{M}_{2}$ and $\mathrm{CuA}_{1}$. This area of wing membrane bears part of the wing pattern normally present between the same veins on the hindwing between veins $\mathrm{M}_{3}$ and $\mathrm{CuA}_{1}$. Interestingly, the hindwing pattern that has been replicated on the forewing is distorted towards the discocellular cell on the underside only, whereas there is no distortion on the non-homeotic side or upper hindwing surface on the specimen.

\section{Discussion}

Homeotic aberrations are relatively rare as evidenced by the exhaustive surveys of museum specimens by Sibatani (1980, 1983a, 1983b), which recorded just over 358 specimens whose phenotype showed any sort of wing pattern homeosis. The specimen of Papilio aegeus ormenus described here is believed to be the only homeotic specimen known from Australia, as no other specimens have been recorded in literature or have been noted in Australian museum collections (E.D. Edwards and D. Britton, pers. comms).

The specimen described here is typical of known butterfly specimens with homeotic wing pattern aberrations (Sibatani 1980, 1983a, 1983b), with the homeosis bounded anteriorly by vein M2. This specimen is, however, unique in that the corresponding part of the hindwing pattern is also aberrant, in that it is distorted anteriorly towards the discocellular vein. Given the hypothesis by Sibatani (1980) that homeotic wing pattern aberrations in butterflies have a genetic basis, it would seem unlikely that the hindwing pattern aberration would have been influenced or caused by the mutation responsible for homeosis of the forewing. A possible explanation is that this aberration is independent of the homeosis and was induced by the larva completing ecdysis to pupa while being transported by light aircraft, with the disruption distorting the imaginal bud. It is also worth noting 


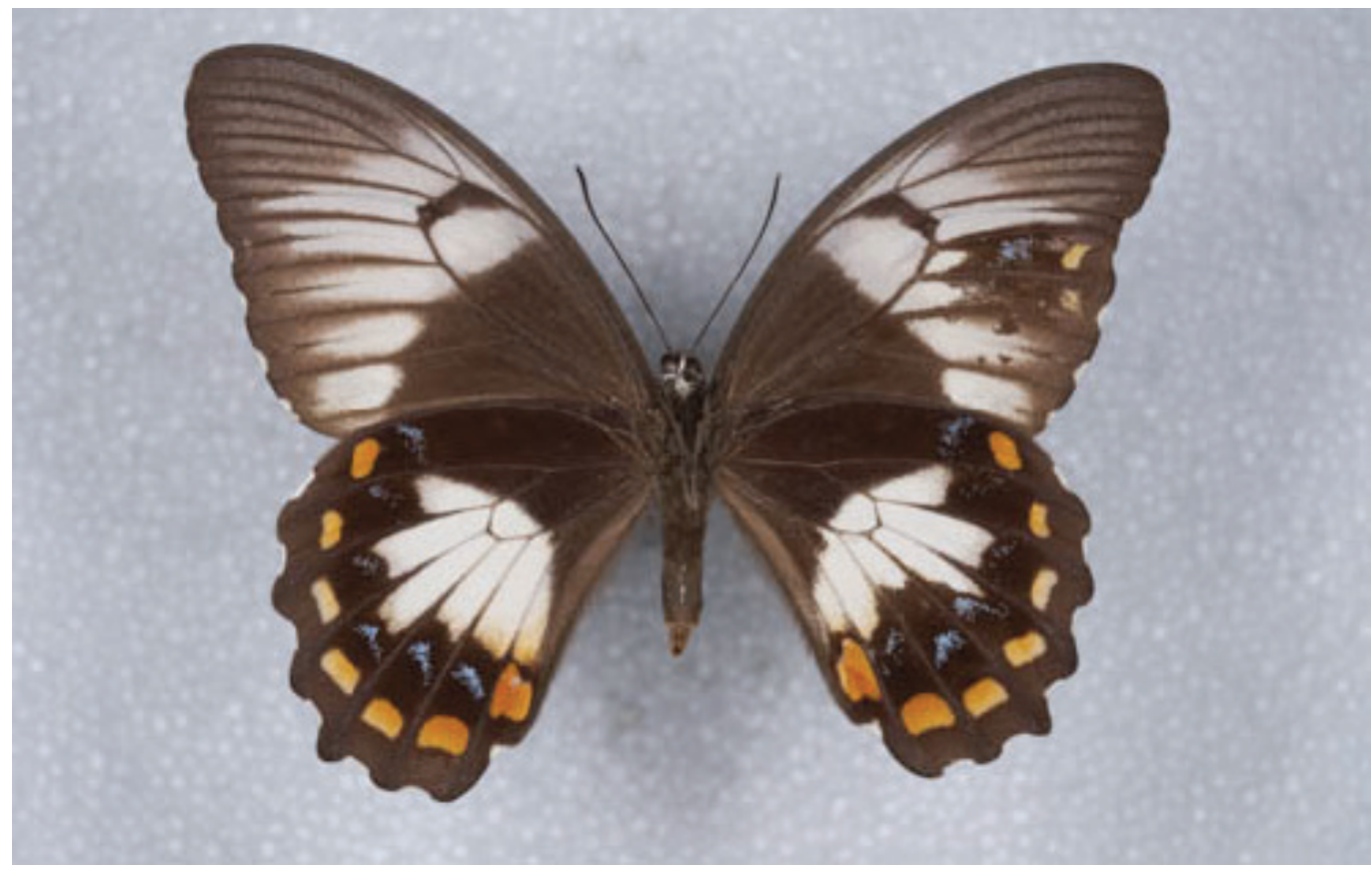

Figure 1. The homeotic specimen of Papilio aegeus ormenus, showing the undersides of the wings. The homeotic aberration is bordered by the discocellular cell and veins $\mathrm{M}_{2}$ and $\mathrm{CuA}$. Note that the distorted pattern on the hindwing is independent of the homeotic markings on the forewings, and is more likely caused by damage sustained by the pupa during ecdysis from the fifth instar.

that the forewing is also slightly deformed on the homeotic side of the specimen between veins $M_{1}$ and $\mathrm{M}_{2}$, which may also have been caused by the same mechanism.

\section{Acknowledgements}

The authors are grateful to E.D. Edwards and D. Britton for discussion regarding records of homeotic butterfly aberrations in Australia, and to D. Lees, D.L. Hancock, A.G. Orr, C. Penz and S. Schachat for their critical review. D. Lees in particular is thanked for his assistance with providing access to literature. G.A. Wood extends his gratitude to the Meriam people, the indigenous inhabitants of Mer Island, for permission to collect insect specimens during his visit in 1984 .

\section{References}

Hancock DL (1983) Princeps aegeus and its allies (Lepidoptera: Papilionidae): systematics, phylogeny and biogeography. Australian Journal of Zoology 31: 771-797. https://doi.org/10.1071/ZO9830771

Lewis EB (1978) A gene complex controlling segmentation in Drosophila. Nature 276: 565-570. https://doi. org/10.1038/276565a0

Parsons M (1999) The Butterflies of Papua New Guinea: Their Systematics and Biology. Academic Press, London. 
Sibatani A (1980) Wing homoeosis in Lepidoptera: a survey. Developmental Biology 79: 1-18. https://doi. org/10.1016/0012-1606(80)90069-X

Sibatani A (1983a) A compilation of data on wing homoeosis in Lepidoptera. Journal of Research on the Lepidoptera 22(1): 1-46.

Sibatani A (1983b) Compilation of data on wing homoeosis in Lepidoptera: Supplement 1. Journal of Research on the Lepidoptera 22(2): 118-125.

\section{Addendum}

Other papers by Wood may be downloaded at http://www.aainsects.com.au 